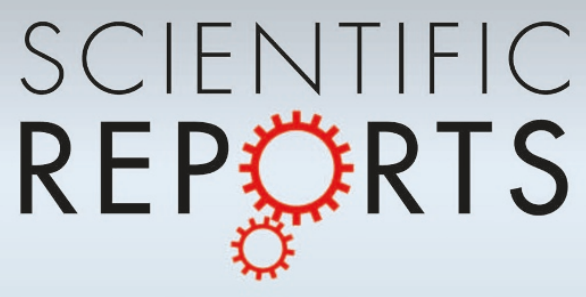

OPEN

SUBJECT AREAS:

POROUS MATERIALS

SYNTHESIS AND PROCESSING

Received

5 September 2014

Accepted

11 November 2014

Published

1 December 2014

Correspondence and requests for materials should be addressed to c.C. (cbcao@bit.edu.

$\mathrm{cn})$

\section{From Rice Bran to High Energy Density Supercapacitors: A New Route to Control Porous Structure of 3D Carbon}

\author{
Jianhua Hou', Chuanbao Cao', Xilan Ma' , Faryal Idrees' , Bin Xu², Xin $\mathrm{Hao}^{2} \&$ Wei Lin²
} ${ }^{1}$ Centre of Materials Science, Beijing Institute of Technology, Beijing 100081, P. R. China, ${ }^{2}$ State Key Laboratory of Chemical
Resource Engineering, Beijing Key Laboratory of Electrochemical Process and Technology for Materials, Beijing University of
Chemical Technology, Beijing 100029, P. R. China.

Controlled micro/mesopores interconnected structures of three-dimensional (3D) carbon with high specific surface areas (SSA) are successfully prepared by carbonization and activation of biomass (raw rice brans) through $\mathrm{KOH}$. The highest SSA of $2475 \mathrm{~m}^{2} \mathrm{~g}^{-1}$ with optimized pore volume of $1.21 \mathrm{~cm}^{3} \mathrm{~g}^{-1}(40 \%$ for mesopores) is achieved for $\mathrm{KOH} / \mathrm{RBC}=4$ mass ratio, than others. The as-prepared $3 \mathrm{D}$ porous carbon-based electrode materials for supercapacitors exhibit high specific capacitance specifically at large current densities of $10 \mathrm{~A} \mathrm{~g}^{-1}$ and $100 \mathrm{~A} \mathrm{~g}^{-1}$ i.e., $265 \mathrm{~F} \mathrm{~g}^{-1}$ and $182 \mathrm{~F} \mathrm{~g}^{-1}$ in $6 \mathrm{M} \mathrm{KOH}$ electrolyte, respectively. Moreover, a high power density ca. $1223 \mathrm{~W} \mathrm{~kg}^{-1}\left(550 \mathrm{~W} \mathrm{~L}^{-1}\right)$ and energy density $70 \mathrm{~W} \mathrm{~h} \mathrm{~kg}^{-1}\left(32 \mathrm{~W} \mathrm{~h} \mathrm{~L}^{-1}\right)$ are achieved on the base of active material loading $\left(\sim 10 \mathrm{mg} \mathrm{cm}^{2}\right)$ in the ionic liquid. The findings can open a new avenue to use abundant agricultural by-products as ideal materials with promising applications in high-performance energy-storage devices.

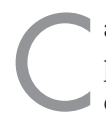

arbon-based electrical double layer capacitors (EDLCs) or supercapacitors offer unique advantages of high power density and extraordinary cyclability but provide moderate energy density ${ }^{1,2}$. Enhancing their energy density without compromising the mentioned advantages would enable their widespread applications $s^{3,4}$. For instance, the ever-increasing market penetration of hybrid electric or fully-electric vehicles (HEVs or EVs) requires not only a continual improvement of the power density during acceleration but also enhance energy density for uninterruptible power supplies ${ }^{5,6}$.

EDLCs are electrochemical capacitors that electrostatically store charge using reversible adsorption of ions of electrolyte onto porous electrode materials with high surface area and pores adapted to the size of ions ${ }^{7-11}$. The high-surface-area $\left(>2000 \mathrm{~m}^{2} \mathrm{~g}^{-1}\right)$ conventional biomass, coal, or petroleum-derived activated carbons (ACs) are already employed in existing commercial EDLC-based devices ${ }^{12}$. Unfortunately, they possess energy density limitations (5-8 $\left.\mathrm{Wh} \mathrm{kg}^{-1}\right)^{13,14}$ for high power density. Microporous guarantee their high specific surface area and low porosity, however, some pores with smaller size than ions prevent efficient ion electroadsorption ${ }^{8}$. Such as, the pores with size of less than $0.5 \mathrm{~nm}$ are generally considered too small to form a double layer, which do not contribute to total double layer capacitance ${ }^{9}$. While ideal micropores should be slightly larger than the de-solvated ions so as these ions passes through pores smoothly ${ }^{7-9}$. Moreover, carbon of exclusively microporous will increase the equivalent resistance and consequently decreased power denisity ${ }^{12-16}$. On the contrary, abundant porous texture combines macroporous and mesoporous ${ }^{17-20}$ may exhibit ultrafast rate capability in applications with improved ionic mass transport inside relatively large pores. However, their limited surface area (typically below $\left.1000 \mathrm{~m}^{2} \mathrm{~g}^{-1}\right)$ and high porosity $\left(\sim 0.3 \mathrm{~g} \mathrm{~cm}^{-3}\right)$ with limited active sites minimizes the energy density of EDLCs, i.e. materials with few micropores and mesopores cause a limited capacity $\left(<120 \mathrm{~F} \mathrm{~g}^{-1}\right.$ in organic electrolytes ${ }^{21,22}$. Several methods have been explored for pore size distribution (PSD)-controlled microporous and mesoporous carbon synthesis for EDLCs ${ }^{13}$. Carbide-derived carbons and templated carbons with controlled pore sizes try to ensure smooth ion transfer, but their relatively sophisticated synthesis process and/or the use of toxic chemicals/gases limit the production in large-scale ${ }^{13}$. In addition, as a renewable resource, biomass has attracted a great deal of attention in preparation of porous carbon materials for supercapacitors ${ }^{12,14,16}$, due to their low cost, huge availability, rapid regeneration and environment friendliness. However, their energy density and rate performance is still unsatisfactory. Therefore, the successful and large-scale commercial popularization of high energy density supercapacitors, in a longer-term perspective, ought to rely on the advantage of huge abundance, 


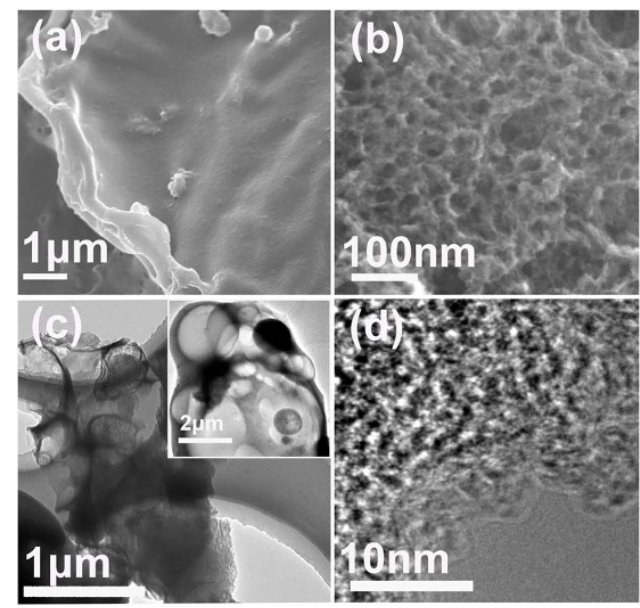

Figure $1 \mid$ the SEM and TEM images. (a) SEM image of RB; (b) SEM image of RBC-4; (c) TEM image of RBC-4 (inset: TEM image of RB) and (d) HR-TEM image of RBC-4.

easy access, direct biomass raw materials for producing ACs synthesis with high surface area and well-controlled DSP both for high capacity and high rate capability.

Rice bran is a by-product of rice milling industry with amazing amount of $2.93 \times 10^{7}$ tons per year all over the globe. It is a multilayers structure composed of pericarp, episperm, aleurone, subaleurone layers and parts of the germ ${ }^{23}$. Usually, rice bran is used as animal feed or discarded as a waste thus frequently causing disposal problems $^{23}$. Rice bran was trying to prepare activated carbon, but its application limited with low surface area $\left(260-652 \mathrm{~m}^{2} \mathrm{~g}^{-1}\right)^{24}$.

In this study, we reported a new route to produce rice bran derived honeycomb-like 3D carbons (RBC-X) via combined precursor carbonization and activation process, which have features of high surface area and well-balanced micro/mesoporosity. The relationship between pores structure of RBC-X and its electrochemical performance are explored in detail. The results show that the sample with high specific surface area of $2475 \mathrm{~m}^{2} \mathrm{~g}^{-1}$ and mesoporous pore volume up to $40 \%$ has the optimum capacitance performance of $182 \mathrm{~F} \mathrm{~g}^{-1}$ at large current densities of $100 \mathrm{~A} \mathrm{~g}^{-1}$ in $6 \mathrm{M} \mathrm{KOH}$. The good stability is also demonstrated by the 10,000 cycle life of charge/discharge. Most importantly, the energy density and power density reached $70 \mathrm{Wh} \mathrm{kg}^{-1}(32 \mathrm{~W} \mathrm{~h}$ $\left.\mathrm{L}^{-1}\right)$ and $1223 \mathrm{~W} \mathrm{~kg}^{-1}\left(550 \mathrm{~W} \mathrm{~L}^{-1}\right)$, respectively, in ionic liquid. The improved electrochemical performances obtained at high current densities are most likely due to large specific surface area and micro/mesoporosity with enhanced active sites. Thus, we provide a kind of readily available, renewable and cheap raw materials for preparation of high energy density EDLCs.

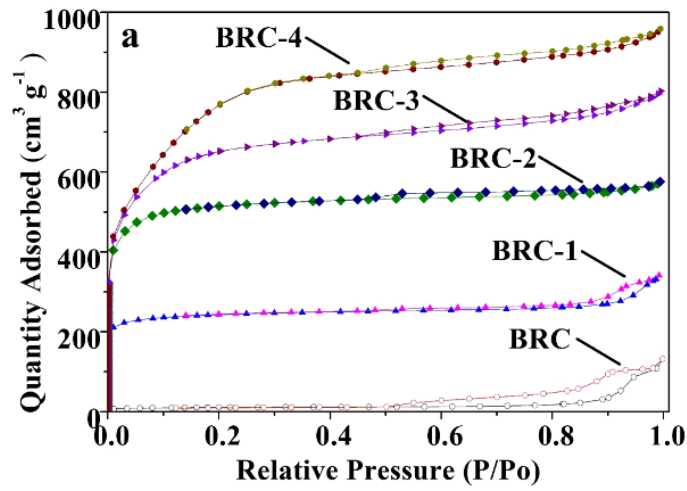

\section{Results and discussion}

The structure and morphology of rice brans (RB) and final products prepared were analyzed by scanning electron microscopy (SEM) and transmission electron microscope (TEM), respectively. The laminar surface of rice bran framework was smooth as shown in Fig. 1a. However, it contains natural pore structure biopolymers in cell wall (inset of Fig. 1c). After $700^{\circ} \mathrm{C}$ carbonized process (RBC), it had low specific surface area (SSA) $33 \mathrm{~m}^{2} \mathrm{~g}^{-1}$ and pore diameters mainly concentrated around $25 \mathrm{~nm}$ and pore volume up to $0.2 \mathrm{~cm}^{3} \mathrm{~g}^{-1}$ (Fig. 2b). After the activation step, the typical $\mathrm{RBC}-4$ provides a unique distribution of interconnected pores of honeycomb-like network structure on surface as shown in Fig. 1b. This network consist of closely linked interconnected few to tens pores, thus forms a perfect hierarchical porous system. RBC-4 takes possession of a unique carbon framework structure from RB precursors confirmed by TEM (Fig. 1c). The meso/micropores and channels can be clearly seen by high resolution TEM (Fig. 1c-d). These interconnected pores of carbon materials provided a favorable path for transportation and penetration of electrolyte ions, which are important for fast ion transfer ${ }^{17-20}$. The elemental analysis shows that $\mathrm{C}, \mathrm{N}, \mathrm{H}$ and $\mathrm{S}$ contents in RBCs, which is consistent with the XPS (Table S1 and Fig. S2). Table S1 shows RBCs materials consist of $C, N, O$ and S. The contents of heteroatoms ( $\mathrm{N}, \mathrm{O}$, and $\mathrm{S}$ ) gradually decrease with increasing activation agents. While corresponding carbon content increases with increasing activation agents i.e. for RBC-4, carbon content is $92.57 \mathrm{wt} . \%$ which is almost equal to YP-17D. Therefore, these porous carbon materials derived from RB could be promising electrode materials for high power density supercapacitors.

Fig. 2a shows nitrogen $(77 \mathrm{~K})$ adsorption-desorption isotherms linear plot of RBC and RBC-X. The porous properties of resultant carbon materials are summarized in Table 1 . It can be seen that surface area increases with almost in linear relation with activation agents i.e. $752 \mathrm{~m}^{2} \mathrm{~g}^{-1}$ for RBC-1, $1592 \mathrm{~m}^{2} \mathrm{~g}^{-1}$ for RBC-2, $2037 \mathrm{~m}^{2}$ $\mathrm{g}^{-1}$ for RBC-3 and $2475 \mathrm{~m}^{2} \mathrm{~g}^{-1}$ for RBC-4. In Fig. $2 \mathrm{~b}$ it can be seen RBC-X have rapid increase of small pores for $<4 \mathrm{~nm}$ while it decreases around $25 \mathrm{~nm}$ of porous volume in comparison of RBC. These changes were marked by arrows in Fig. 2b. Besides, when the weight ratio (regenerated $\mathrm{KOH} / \mathrm{RBC}$ ) was greater than 2 , the volume of micropores was almost equal while the volume of mesopores rapidly increased. These results demonstrate that an increase in the amount of $\mathrm{KOH}$ not only effectively enhance RBC-X specific surface area but also mesoporous volume. In addition, the electrode density of RBC-X are $0.45-0.78 \mathrm{~g} \mathrm{~cm}^{-3}$, which is similar to that of commercial ACs $\left(\sim 0.5 \mathrm{~g} \mathrm{~cm}^{-3}\right)$ and higher than that of graphene or CNT materials $\left(\sim 0.3 \mathrm{~g} \mathrm{~cm}^{-3}\right)^{2}$. Furthermore, a maximum specific surface area of $2475 \mathrm{~m}^{2} \mathrm{~g}^{-1}$ and pore volume $1.21 \mathrm{~cm}^{3} \mathrm{~g}^{-1}$ with mesoporous volume up to $40 \%$ was achieved with a $\mathrm{KOH}$ to $\mathrm{RBC}$ ratio of 4 . The higher surface area mesoporous pore volume and narrower pore size distribution of RBC-4 are advantageous for fast ions transfer and charge storage. Furthermore, the electrical conductivity of the

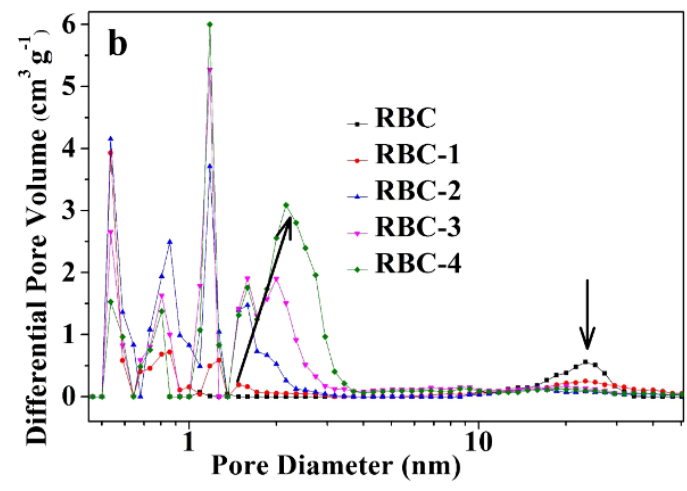

Figure 2 Nitrogen adsorption/desorption isotherms. (a) DFT pore-size distribution curve (b) of RBC and RBC-X. 


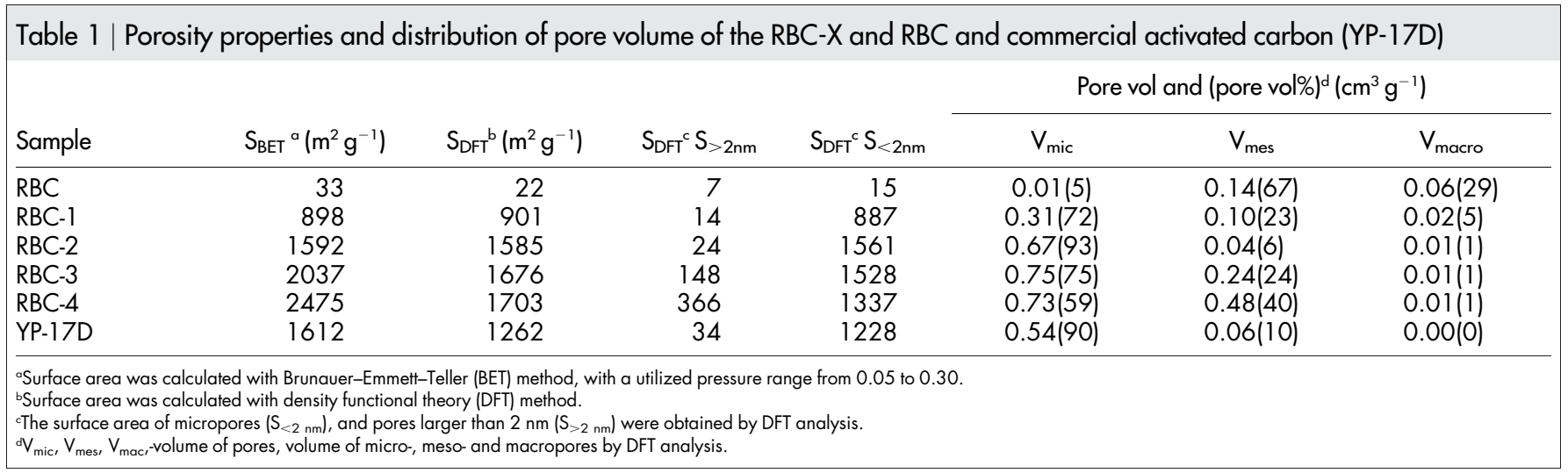

RBC-4 powder and RBC-4 based electrode are $\sim 13.8 \mathrm{~S} \mathrm{~m}^{-1}$, and $\sim 21.6 \mathrm{~S} \mathrm{~m}^{-1}$, respectively. These are superior than previously reports related to other biomass-based porous carbon $^{36,38}$.

The performance of these RBC-X samples as supercapacitors electrodes was characterized by cyclic voltammetry $(\mathrm{CV})$ measurements
(Fig. 3a).The cyclic voltammetry (CV) curves showed nearly symmetrical rectangular shapes, indicative of an ideal capacitive behavior. However, small and highly distorted CV curves for RBC-1 relative to $\mathrm{RBC}-4$ at a relatively scan rate of $100 \mathrm{mV} \mathrm{s}{ }^{-1}$ were seen. As shown in Fig. 3b, a higher KOH/RBC mass ratio led to a longer
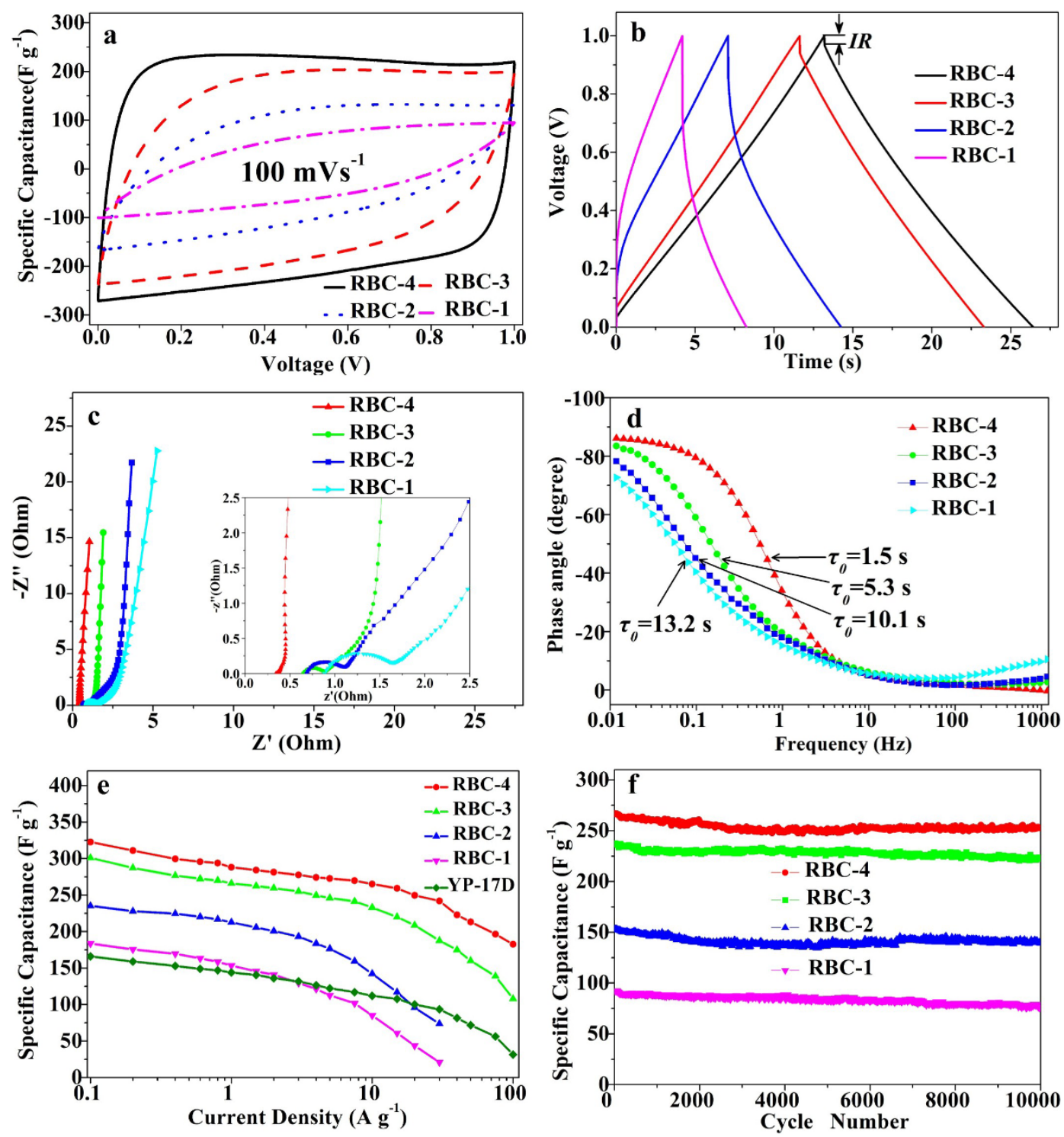

Figure 3 Electrochemical performance characteristics of RBC-X measured in a two-electrode system in the $6 \mathrm{M} \mathrm{KOH}$ electrolyte. (a) CV curves at the scan rate of $100 \mathrm{mV} \mathrm{s}^{-1}$; (b) Galvanostatic charge-discharge curves at high current density of $10 \mathrm{~A} \mathrm{~g}^{-1}$; (c) Nyquist plots and (d) Bode plots of phase angle versus frequency; (e) Specific capacitances at different current densities; (f) Cycling stability at $10 \mathrm{~A} \mathrm{~g}^{-1}$. 

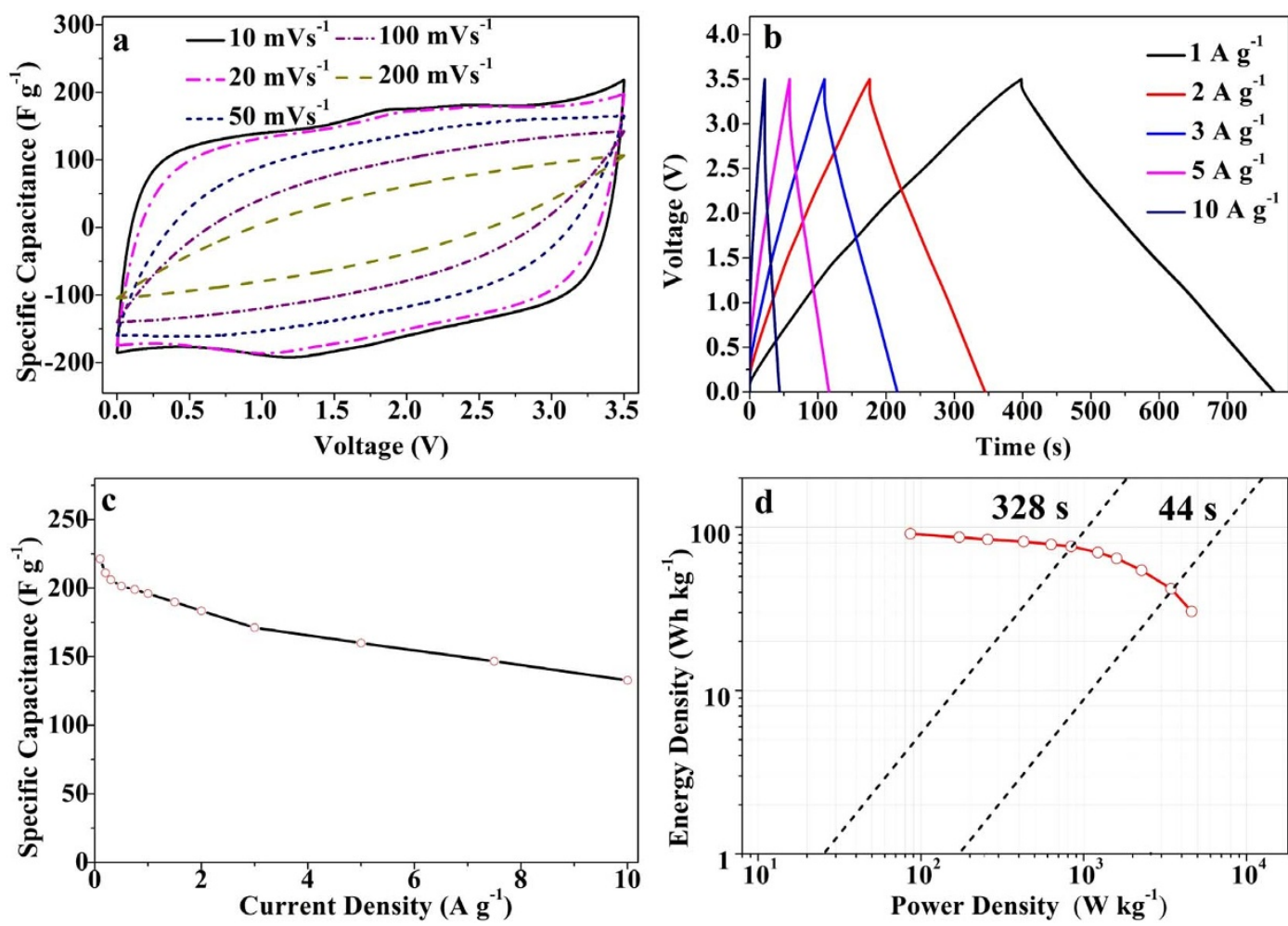

Figure 4 Electrochemical performance of $\mathrm{RBC}-4$ in a two-electrode system using the ionic liquid $\mathrm{EMIMBF}_{4}$ electrolytes. (a) CV curves at various scan rates; (b) Galvanostatic charge/discharge curves under different current densities; (c) Specific capacitance as a function of the current densities; (d) Ragone plot of symmetrical RBC-4 based supercapacitors.

discharge times at a same charging-discharge rate. In addition, $\mathrm{RBC}$ 4 and RBC-3 can be charged and discharged smoothly with symmetric and well-defined charge-discharge lines at a high current density of $10 \mathrm{~A} \mathrm{~g}^{-1}$ (Fig. 3b). However, RBC-2 and RBC-1 show large IR drop, even non-linear charge-discharge curves at the same current density. This might be due to larger surface area that promote ion adsorption space and large sized pores that promote ion diffusion $^{17-20}$. The higher effective specific surface area and pore volume of RBC-4 exhibited the highest excellent cyclic voltammetry and galvanostatic charge-discharge character (Fig. 3a-b), indicating that the RBC-4 is the most promising material for supercapacitors electrodes.

Fig. $3 c$ gives further evidence that the RBC-4 shows an almost vertical curve in the low frequency region, indicating good capacitance behavior in a frequency range from $100 \mathrm{kHz}$ to $0.01 \mathrm{~Hz}$. And from the high frequency region (inset in Fig. 3c), not only RBC-4 have a relatively low equivalent series resistance than others but also they showed the much shorter Warburg region portion (the slope of the $45^{\circ}$ portion of the curve) than others for better ion diffusion efficiency ${ }^{25-27}$. Smaller contact resistance among the material and ion produce low equivalent series resistance (ESR) for RBC-4. ESR increases by intrinsic electronic properties of electrolyte solution and electrode matrix. This behavior associates to excellent intrinsic electronic properties of material, mass transmit resistance of the ions in the matrix and contact resistance among the electrode and current collector ${ }^{25,28}$. The corresponding time constant $\tau_{0}^{29}$ (the inverse of the characteristic frequency at which $-45^{\circ}$ is reached in the Bode phase plots) also responded in a similar fashion (Fig. $3 \mathrm{~d}$ ). The $\tau_{0}$ decreased 2.5 times from 13.2 to $5.3 \mathrm{~s}$ as the activating agent $\mathrm{KOH}$ to $\mathrm{RBC}$ of weight ratio increased 3 times. By contrast, activating agent $\mathrm{KOH}$ to $\mathrm{RBC}$ of weight ratio less than $34 \%$ change in $\mathrm{KOH}$ to $\mathrm{RBC}$ of weight ratio from the RBC-3 to RBC-4 gave a shift of $\tau_{0}$ decreased 3.5 times to $1.5 \mathrm{~s}$. The above results indicated that highly efficient ion transport channels retained in RBC-4. These results demonstrate that the
RBC-4-based material is very suitable for high-rate and highly stable supercapacitors applications. In order to further investigate the high performance of RBC-4, cyclic voltammograms at various scan rates and galvanostatic charge-discharge curves at various current densities were checked (Fig. S4). RBC-4 still exhibited typical capacitive behavior with rectangular shaped voltammetry characteristics even at a high potential scan rate of $500 \mathrm{mV} \mathrm{s}^{-1}$, indicating fast and efficient charge transfer rate (Fig. S4a). At a current density of $0.1 \mathrm{~A} \mathrm{~g}^{-1}$, the specific capacitances (surface area normalized capacitance values based on the BET surface area): $323\left(13.1 \mu \mathrm{F} \mathrm{cm}^{-2}\right)$, 301 $\left(14.8 \mu \mathrm{F} \mathrm{cm} \mathrm{cm}^{-2}\right), 235\left(14.8 \mu \mathrm{F} \mathrm{cm} \mathrm{cm}^{-2}\right)$, and $184 \mathrm{~F} \mathrm{~g}^{-1}(20.5 \mu \mathrm{F}$ $\mathrm{cm}^{-2}$ ) were obtained for RBC-4, RBC-3, RBC-2, and RBC-1, respectively (Fig. 3e). The specific capacitances based on surface area efficiently increase, with the increase of heteroatoms contents $(\mathrm{N}$, and $\mathrm{O})$. This may be attributed to large content of heteroatoms ( $\mathrm{N}$, and O) enhances the capacitance with same pseudocapacitive effect $^{30,33}$. However, RBC-4 have the largest specific surface area, therefore also have highest capacitance value than others. These values are much higher than those determined for the activated carbon YP-17D (168 $\mathrm{F} \mathrm{g}^{-1}, 10.4 \mu \mathrm{F} \mathrm{cm}^{-2}$ ) and are comparable or superior to those achieved with advanced activated carbons $s^{15,32,34,35}$. This result suggests a good match between the pore size and electrolyte ions size. On the other hand, at higher current density the specific capacitance slightly decreased due to an inadequate time for electrolyte diffusion into inner pores. However, at a current density of $10 \mathrm{~A} \mathrm{~g}^{-1}, \mathrm{RBC}-4$ and RBC-3 still maintained specific capacitances of $265 \mathrm{~F} \mathrm{~g}^{-1}(82 \%$ capacitance retention) and $233 \mathrm{~F} \mathrm{~g}^{-1}$ (77\% capacitance retention), respectively (Fig. 3e). Even at $100 \mathrm{~A} \mathrm{~g}^{-1}$, a capacitance of $182 \mathrm{~F} \mathrm{~g}^{-1}$ was retained for RBC-4. This result might be due to mesopores formed in the carbon materials are vital for furnishing a smooth and convenient ion-transfer pathway and thus enhanced electrolyte accessibility to the microporous area, which was further proved the importance of creating easy electron/ion-transport pathways in pursuit of high-rate supercapacitors materials. Therefore, electrochem- 
ical performances of the RBC- 4 could be better than previously reports (other biomass-based porous carbon) ${ }^{31,32,33}$, and even superior to some advanced carbon materials for high power supercapacitors, such as pseudo-capacitance exists nitrogen-doped carbons ${ }^{31,32}$ $\left(154 \mathrm{~F} \mathrm{~g}^{-1}\right.$ at $50 \mathrm{mV} \mathrm{s}^{-1}, 120 \mathrm{~F} \mathrm{~g}^{-1}$ at $52.5 \mathrm{~A} \mathrm{~g}^{-1}, 112 \mathrm{~F} \mathrm{~g}^{-1}$ at $100 \mathrm{~A}$ $\left.\mathrm{g}^{-1}\right)$, carbon nanocages ${ }^{34}\left(112 \mathrm{~F} \mathrm{~g}^{-1}\right.$ at $\left.100 \mathrm{~A} \mathrm{~g}^{-1}\right)$, coPIL-RGO ${ }^{35}$ and graphene films ${ }^{29}\left(120-160 \mathrm{~F} \mathrm{~g}^{-1}\right.$ at $\left.50 \mathrm{~A} \mathrm{~g}^{-1}\right)$. The RBC-X displayed an extraordinary high stability after 10000 cycles at a high current density of $10 \mathrm{~A} \mathrm{~g}^{-1}$, but RBC-4 showed higher specific capacitances (Fig. 3f).

In order to explore supercapacitors for its broad applications at high energy density, ionic liquid $\mathrm{EMIMBF}_{4}$ as electrolyte was used as its potential window is 3.5 times larger than aqueous electrolyte. The typical rectangular $\mathrm{CV}$ curve from 0 to $3.5 \mathrm{~V}$ was obtained even at $100 \mathrm{mV} \mathrm{s}^{-1}$ of scan rate (Fig. 4a), indicating fast and efficient charge transfer. The RBC-4 show excellent performance with a high specific capacitance at a current density of $0.1 \mathrm{~A} \mathrm{~g}^{-1}$, and retain the high values of $196 \mathrm{~F} \mathrm{~g}^{-1}$ and $133 \mathrm{~F} \mathrm{~g}^{-1}$ even at a high current density of $1 \mathrm{~A} \mathrm{~g}^{-1}$ and $10 \mathrm{~A} \mathrm{~g}^{-1}$, respectively (Fig. 4c). Which was higher than that of the carbons derived from silk proteins ${ }^{32}$, human hair $^{33}$, leaves $^{36}$, hemp ${ }^{37}$, potassium citrate $^{38}$, and Pistachio nutshell ${ }^{39}$ $\left(168 \mathrm{~F} \mathrm{~g}^{-1}\right.$ at $0.8 \mathrm{~A} \mathrm{~g}^{-1}$, and $107 \mathrm{~F} \mathrm{~g}^{-1}, 88 \mathrm{~F} \mathrm{~g}^{-1}$ at $2 \mathrm{~A} \mathrm{~g}^{-1}$, and $158 \mathrm{~F} \mathrm{~g}^{-1}$ and $138 \mathrm{~F} \mathrm{~g}^{-1}$ at $1 \mathrm{~A} \mathrm{~g}^{-1}$, and $97 \mathrm{~F} \mathrm{~g}^{-1}$ at $8 \mathrm{~A} \mathrm{~g}^{-1}$ ), and even superior to some novel carbon materials such as a$\mathrm{MEGO}^{40}$ (activated microwave-expanded graphite oxide), compressed a-MEGO ${ }^{41}$, carbon nanotubes arrays $s^{42}$, nanocarbons ${ }^{43}$ and carbide-derived carbon ${ }^{44}\left(120 \mathrm{~F} \mathrm{~g}^{-1}-170 \mathrm{~F} \mathrm{~g}^{-1}\right.$ at a current density of $\left.1 \mathrm{~A} \mathrm{~g}^{-1}\right)$. The Ragone plot for the symmetrical RBC-4 based device (Fig. 4d) shows that the specific energy density is about $91.4 \mathrm{~W} \mathrm{~h}$ $\mathrm{kg}^{-1}\left(41.1 \mathrm{~W} \mathrm{~h} \mathrm{~L}^{-1}\right)$ at a current density of $0.1 \mathrm{~A} \mathrm{~g}^{-1}$ which is superior or comparable to the commercial devices (i.e., EDLCs $<8 \mathrm{Wh}$ $\mathrm{kg}^{-1}$, pseudocapacitors $\left.<30 \mathrm{~W} \mathrm{~h} \mathrm{~kg}{ }^{-1}\right)^{2,14}$, hybrid supercapacitor $\left(55 \mathrm{Wh} \mathrm{kg}^{-1}\right)^{43}$ and those achieved with advanced activated carbons ${ }^{31-41,44,45}$. The power density and energy density values found are $1223 \mathrm{~W} \mathrm{~kg}^{-1}\left(550 \mathrm{~W} \mathrm{~L}^{-1}\right)$ and $70 \mathrm{~W} \mathrm{~h} \mathrm{~kg}^{-1}\left(32 \mathrm{~W} \mathrm{~h} \mathrm{~L}^{-1}\right)$, respectively. Also, the electrodes have high carbon loading of $\sim 10 \mathrm{mg} \mathrm{cm}{ }^{-2}$. This suggests that BBC-4 based electrodes can be prepared at industrial level which will give high electrochemical performance energy storage devices. Through EIS results in Fig. S5, not only RBC-4 has a relatively low equivalent series resistance, but also it showed the much shorter Warburg region portion.

The following factors could be summarized to elucidate the important aspects of high capacity and excellent rate capacity performance achieved in rice bran-based porous carbon based supercapacitors. First, synthesized honeycomb-like 3D porous carbon structure synthesis possess intrinsic natural pore channels framework structure provides interconnected ion channels facilitate contact between ion and material and is also attributable to good intrinsic electronic conductivity properties of material, provide fast ion channels and short diffusion distance to facilitate ion transport or decreasing the electric resistance. Second, RBC-4 has an ultrahigh specific surface area of $2475 \mathrm{~m}^{2} \mathrm{~g}^{-1}$ with wellbalanced micro/mesoporosity and optimized-controlled DSP which can provide rich sites for adsorbing ions, resulting in large capacitance. For example, our smallest microporous materials peak at $0.55 \mathrm{~nm}$ slightly larger than the size of the de-solvated ions that could be electrochemically accessible for aqueous electrolytes ${ }^{2,3,5,7}$. And $0.55 \mathrm{~nm}$ pore size is an optimized pore size for high capacitance EDLCs in $6 \mathrm{M} \mathrm{KOH}^{46}$. Finally, the abundant mesopore, not only provided a large interface between the electrode and the electrolyte for maintaining good ion transport and adsorbing ions, but also help in the transport of the ions from the surface to the bulk of the electrode so that the micropores can be accessed properly ${ }^{16-19}$. Therefore, electrochemical performance of $\mathrm{RBC}-4$ is better than other advanced porous carbon materials as shown in Table S2.

\section{Conclusions}

3D porous carbon with optimized DSP, high SSA and high density was prepared by using a facile, cost-effective, and scalable synthesis route. Highly abundant and easily accessible direct biomass raw material was obtained through rice brans as a carbon source. The higher SSA and well-balanced micro/mesopores interconnected structure of RBC-4 was used for supercapacitors electrode material. The prepared EDLCs showed a specific capacitance of $265 \mathrm{~F} \mathrm{~g}^{-1}$ at large current densities of $10 \mathrm{~A} \mathrm{~g}^{-1}$ in aqueous electrolytes, a stable cycle life over 10,000 cycle, a specific energy of $70 \mathrm{Wh} \mathrm{kg}^{-1}\left(32 \mathrm{~W} \mathrm{~h} \mathrm{~L}^{-1}\right)$ and a specific power of $1223 \mathrm{~W} \mathrm{~kg}^{-1}$ $\left(550 \mathrm{~W} \mathrm{~L}^{-1}\right)$ in ionic liquid. The developed approach can be useful in designing and producing a variety of novel activated carbons with promising applications in high performance energy storage devices.

\section{Experimental section}

Synthesis. Rice bran used in this study was obtained from a rice mill in the Anhui Province, China. Potassium hydroxide $(\mathrm{KOH})$ and hydrochloric acid $(\mathrm{HCl})$ used are of analytical grade. 1-Ethyl-3-methylimidazolium tetrafluoroborate

$\left(\mathrm{EMIMBF}_{4}>99 \%\right.$, water content $\left.<100 \mathrm{ppm}\right)$ was purchased from Linzhou Branch to Materials Science and Technology Co.

First, $15 \mathrm{~g}$ of Rice brans (RB) are carbonized in $\mathrm{N}_{2}$ atmosphere at a rate of $3^{\circ} \mathrm{C}$ $\mathrm{min}^{-1}$ from room temperature to $700^{\circ} \mathrm{C}$ for 1 hour. The $\mathrm{RB}$ carbonized material (RBC) was activated with $\mathrm{KOH}$ in $\mathrm{N}_{2}$ atmosphere at a rate of $3^{\circ} \mathrm{C} \mathrm{min}^{-1}$ up to $850^{\circ} \mathrm{C}$ for 1 hour. The resulting dark solid was ground to powder, washed with $1 \mathrm{M} \mathrm{HCl}$ solution and distilled water. Finally, the samples were dried at $120^{\circ} \mathrm{C}$ for $12 \mathrm{~h}$. The obtained samples were named RBC-X where X represents the mass ratio of solid $\mathrm{KOH}$ to RBC.

Characterization. $\mathrm{N}_{2}(77 \mathrm{~K})$ adsorption was conducted from relative pressure $\mathrm{p} / \mathrm{p}^{0}$ of $3.5 \times 10^{-7}-0.998$ to assess the porosity and surface area data of the carbons using a Micromeritics ASAP 2020. Before measurements, the samples were outgassed at $300^{\circ} \mathrm{C}$ for $6 \mathrm{~h}$. The specific surface area and pore size distributions were calculated by the conventional Brunauer-Emmett-Teller (BET) method and density functional theory (DFT) method. Hitachi field-emission scanning electron microscopy (FE-SEM S-4800) and TEM (JEOL JEM-2100F, $200 \mathrm{keV}$ ) were used to analyse the size and morphology of the samples. The size of pores was observed with HRTEM. The conductivity is measured by KEITHLEY 4200-SCS from Keithley Instruments Inc.

Electrochemical measurements. The electrochemical performance of the RBC-X was measured in a symmetrical two-electrode cell. The electrodes were prepared by a mixture of 85 wt.\% of sample, 10 wt.\% of acetylene black and 5 wt.\% of PTFE binder into pellets (10 $\mathrm{mm}$ in diameter) and stainless steel mesh and aluminum mesh were used as current collectors for EDLCs with $6 \mathrm{M} \mathrm{KOH}$ and $\mathrm{EMIMBF}_{4}$ as electrolytes, respectively. The electrode films were dried under vacuum at $120^{\circ} \mathrm{C}$ for $6 \mathrm{~h}$, and then applying a pressure of $10 \mathrm{MPa}$ (30 seconds). The mass of electrode films were 8$11 \mathrm{mg}$ loading in $1 \mathrm{~cm}^{2}$ area. The calculated densities of electrode material were provided in Supporting Information S1. Polypropylene membrane was used as separator for supercapacitors.

The cyclic voltammetry (CV), galvanostatic charge/discharge and AC impedance spectroscopy (EIS) were recorded by the CHI660D electrochemical workstation. The frequency range for the impedance spectra was from $0.01 \mathrm{~Hz}$ to $100 \mathrm{kHz}$ with $\pm 5 \mathrm{mV}$ voltage amplitude. The cutoff charge voltage for the capacitor using $6 \mathrm{M}$ $\mathrm{KOH}$ and $\mathrm{EMIMBF}_{4}$ was set as $0-1.0 \mathrm{~V}$ and $0-3.5 \mathrm{~V}$, respectively. The specific capacitance values of a single electrode were calculated according to Equation (1), with the formula

$$
c_{g}=\frac{2 I}{(d V / d t) m}
$$

Where $I(\mathrm{~A})$ is the discharge current, $d V / d t\left(\mathrm{~V} \mathrm{~s}^{-1}\right)$ is the slope of the discharge curve after the ohmic drop and $m(\mathrm{~g})$ is the mass of the active material in a single electrode. The energy density $\left(E_{\text {cell }}\right)$, and power density $\left(P_{\text {cell }}\right)$ are also calculated according to equation $(2,3)$

$$
\begin{gathered}
E_{\text {cell }}=\frac{c_{g} \Delta V}{8 \times 3.6} \\
P_{\text {cell }}=\frac{E_{\text {cell }}}{t}
\end{gathered}
$$

Where $\left.E_{\text {cell }} \mathrm{W} \mathrm{h} \mathrm{kg}{ }^{-1}\right)$ is the specific energy density, $P_{\text {cell }}\left(\mathrm{W} \mathrm{kg}^{-1}\right)$ is the specific power density of the symmetrical supercapacitors system, where $\Delta V(\mathrm{~V})$ is the cell voltage after ohmic drop, and $\mathrm{t}(\mathrm{h})$ is the discharge time, respectively. 
1. Conway, B. E. Electrochemical supercapacitors: scientific fundamentals and technological applications. (Kluwer Academic/Plenum Publishers, New York, 1999).

2. Simon, P. \& Gogotsi, Y. Capacitive energy storage in nanostructured carbonelectrolyte systems. Acc. Chem. Res. 46, 1094-1103 (2013).

3. Miller, J. R. \& Simon, P. Materials science electrochemical capacitors for energy management. Science 321, 651-652 (2008).

4. Staaf, L. G. H., Lundgren, P. \& Enoksson, P. Present and future supercapacitor carbon electrode materials for improved energy storage used in intelligent wireless sensor systems. Nano Energy 9, 128-141(2014).

5. Simon, P. \& Gogotsi, Y. Materials for electrochemical capacitors. Nat. Mater. 7, 845-854 (2008).

6. Jiang, J. et al. Evolution of disposable bamboo chopsticks into uniform carbon fibers: a smart strategy to fabricate sustainable anodes for Li-ion batteries. Energy Environ. Sci. 7, 2670-2679 (2014).

7. Chmiola, J. et al. Anomalous increase in carbon capacitance at pore size below $1 \mathrm{~nm}$. Science 313, 1760-1763 (2006).

8. Huang, J. S., Sumpter, B. G. \& Meunier, V. Teoretical model for nanoporous carbon supercapacitors. Angew. Chem. Int. Ed. 47, 520-524 (2008).

9. Pandolfo, A. G. \& Hollenkamp, A. F. Carbon properties and their role in supercapacitors. J. Power Sources. 157, 11-27 (2006).

10. Largeot, C. et al. Relation between the ion size and pore size for an electric doublelayer capacitor. J. Am. Chem. Soc. 130, 2730-2731 (2008).

11. Kondrat, S., Wu, P., Qiao, R. \& Kornyshev, A. A. Accelerating charging dynamics in subnanometre pores. Nat. Mater. 13, 387-393 (2014).

12. Wang, H., Li, Z. \& Mitlin, D. Tailoring Biomass-Derived Carbon Nanoarchitectures for High-Performance Supercapacitors. Chemelectrochem 1, 332-337 (2013).

13. Béguin, F., Presser, V., Balducci, A. \& Frackowiak, E. Carbons and electrolytes for advanced supercapacitors. Adv. Mater. 26, 2219-2251 (2014).

14. Sevilla, M. \& Mokaya, R. Energy Storage Applications of Activated Carbons: Supercapacitors and Hydrogen Storage. Energy Environ. Sci. 7, 1250-1280 (2014).

15. Li, Z. et al. Synthesis of well defined microporous carbons by molecular scale templating with POSS moieties. J. Am. Chem. Soc. 136, 4805-4808 (2014).

16. Dutta, S., Bhaumik, A. \& Wu, K. C.-W. Hierarchically porous carbon derived from polymers and biomass: effect of interconnected pores on energy applications. Energy Environ. Sci. 7, 3574-3592 (2014)

17. Wang, D. W. et al. 3D aperiodic hierarchical porous graphitic carbon material for high-rate electrochemical capacitive energy storage. Angew. Chem. Int. Ed. 47, 373-376 (2008).

18. Wu, Z. S. et al. Three-dimensional graphene-based macro-and mesoporous frameworks for high-performance electrochemical capacitive energy storage. J. Am. Chem. Soc. 134, 19532-19535 (2012).

19. Li, Y., Li, Z. \& Shen, P. K. Simultaneous Formation of Ultrahigh Surface Area and Three-Dimensional Hierarchical Porous Graphene-Like Networks for Fast and Highly Stable Supercapacitors. Adv. Mater. 25, 2474-2480 (2013).

20. Sheng, K., Sun, Y., Li, C., Yuan, W. \& Shi, G. Ultrahigh-rate supercapacitors based on eletrochemically reduced graphene oxide for ac line-filtering. Sci. Rep. 2, 247-251 (2012).

21. Li, C. \& Shi, G. Q. Three-dimensional graphene architectures. Nanoscale 4, 5549-5563 (2012)

22. Sun, Y. Wu, Q. \& Shi, G. Q. Graphene based new energy materials. Energy Environ. Sci. 4, 1113-1132 (2011).

23. Sharif, M. K. et al. Rice Bran: A Novel Functional Ingredient. Crit Rev Food Sci Nutr. 54, 807-816 (2014).

24. Suzuki, R. M., Andrade, A. D., Sousa, J. C. \& Rollemberg, M. C. Preparation and characterization of activated carbon from rice bran. Bioresour Technol. 98, 1985-1991 (2007)

25. Zhang, L. L. \& Zhao, X. S. Carbon-based materials as supercapacitor electrodes. Chem. Soc. Rev. 38, 2520-2531 (2009).

26. Wang, Y. et al. Supercapacitor devices based on graphene materials. The Journal of Physical Chemistry C. 113, 13103-13107 (2009).

27. Zhang, L. et al. High-performance supercapacitor electrode materials prepared from various pollens. Small 9, 1342-1347 (2013).

28. Li, Y., Li, Z. \& Shen, P. K. Simultaneous Formation of Ultrahigh Surface Area and Three-Dimensional Hierarchical Porous Graphene-Like Networks for Fast and Highly Stable Supercapacitors. Adv. Mater. 25, 2474-2480 (2013).

29. Yang, X., Cheng, C., Wang, Y., Qiu, L. \& Li, D. Liquid-mediated dense integration of graphene materials for compact capacitive energy storage. Science 341, 534-537 (2013)
30. Zhao, L. et al. Nitrogen-Containing Hydrothermal Carbons with Superior Performance in Supercapacitors. Adv. Mater. 22, 5202-5206 (2010).

31. Liang, Y., Wu, D. \& Fu, R. Carbon microfibers with hierarchical porous structure from electrospun fiber-like natural biopolymer. Sci. Rep. 3, 1119-1123 (2013).

32. Yun, Y. S. et al. Microporous carbon nanoplates from regenerated silk proteins for supercapacitors. Adv. Mater. 25, 1993-1998 (2013).

33. Qian, W. et al. Human hair-derived carbon flakes for electrochemical supercapacitors. Energy Environ. Sci. 7, 379-386 (2014).

34. Xie, K. et al. Carbon Nanocages as Supercapacitor Electrode Materials. Adv. Mater. 24, 347-351 (2012).

35. Mao, L., Li, Y., Chi, C., On Chan, H. S. \& Wu, J. Conjugated polyfluorene imidazolium ionic liquids intercalated reduced graphene oxide for high performance supercapacitor electrodes. Nano Energy 6, 119-128 (2014).

36. Biswal, M., Banerjee, Deo, A. M. \& Ogale, S. From dead leaves to high energy density supercapacitors. Energy Environ. Sci. 6, 1249-1259 (2013).

37. Wang, H. et al. Interconnected Carbon Nanosheets Derived from Hemp for Ultrafast Supercapacitors with High Energy. ACS Nano 7, 5131-5141(2013).

38. Sevilla, M. \& Fuertes, A. B. Direct Synthesis of Highly Porous Interconnected Carbon Nanosheets and Their Application as High-Performance Supercapacitors. ACS Nano 8, 5069-5078 (2014).

39. Xu, J. D. et al. Preparing two-dimensional microporous carbon from Pistachio nutshell with high areal capacitance as supercapacitor materials. Sci. Rep. 4, 5545-5550 (2014).

40. Zhu, Y. et al. Carbon-based supercapacitors produced by activation of graphene. Science 332, 1537-1541 (2011).

41. Murali, S. et al. Volumetric capacitance of compressed activated microwaveexpanded graphite oxide (a-MEGO) electrodes. Nano Energy 2, 764-768 (2013).

42. Izadi-Najafabadi, A. et al. Extracting the full potential of single-walled carbon nanotubes as durable supercapacitor electrodes operable at $4 \mathrm{~V}$ with high power and energy density. Adv. Mater. 22, E235-E241 (2010).

43. Korenblit, Y. et al. High-Rate Electrochemical Capacitors Based on Ordered Mesoporous Silicon Carbide-Derived Carbon. ACS Nano 4, 1337-1344 (2010).

44. Zhang, H., Zhang, X., Sun, X. \& Ma, Y. Shape-controlled synthesis of nanocarbons through direct conversion of carbon dioxide. Sci. Rep. 3, 3534-3541 (2013).

45. Lei, Y. et al. Porous mesocarbon microbeads with graphitic shells: constructing a high-rate, high-capacity cathode for hybrid supercapacitor. Sci. Rep. 3, 2477-2482 (2013).

46. Xu, B. et al. Ultramicroporous carbon as electrode material for supercapacitors. J. Power Sources 228, 193-197 (2013).

\section{Acknowledgments}

This work was supported by a grant from the National Natural Science Foundation (NNSF) of China (no.50972017)

\section{Author contributions}

C.-B.C. designed the experiments. J.-H.H. prepared the samples and performed the experiments. B.X., F.I., X.-L.M., X.H., W.L. participated in interpreting and analyzing the data. All the authors reviewed and commented on the manuscript. C.-B.C., J.-H.H. wrote the manuscript.

\section{Additional information}

Supplementary information accompanies this paper at http://www.nature.com/ scientificreports

Competing financial interests: The authors declare no competing financial interests.

How to cite this article: Hou, J. et al. From Rice Bran to High Energy Density Supercapacitors: A New Route to Control Porous Structure of 3D Carbon. Sci. Rep. 4, 7260; DOI:10.1038/srep07260 (2014)

(c) (i) (2) This work is licensed under a Creative Commons Attribution-NonCommercialShareAlike 4.0 International License. The images or other third party material in this article are included in the article's Creative Commons license, unless indicated otherwise in the credit line; if the material is not included under the Creative Commons license, users will need to obtain permission from the license holder in order to reproduce the material. To view a copy of this license, visit http:// creativecommons.org/licenses/by-nc-sa/4.0/ 